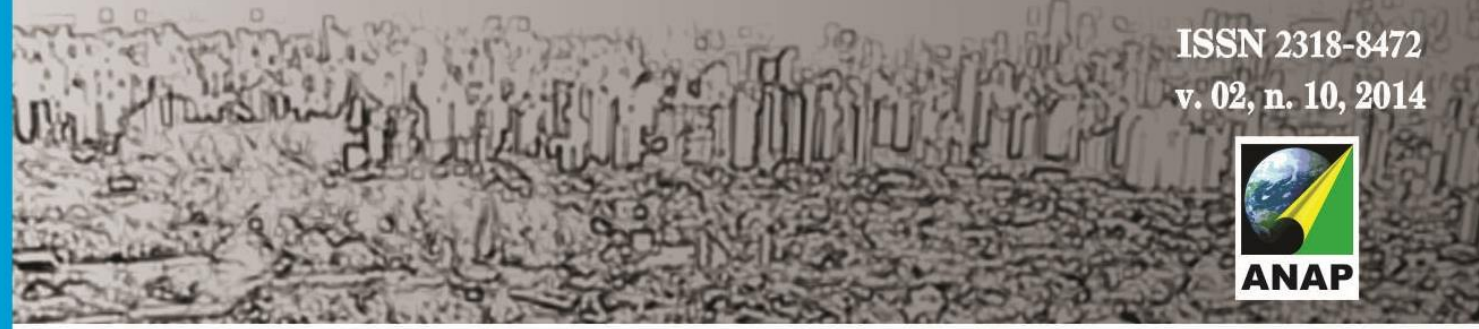

Revista Nacional de

Gerenciamento de Cidades

\title{
SEGREGAÇÃO SOCIOESPACIAL NA CIDADE DE PENÁPOLIS/SP: O CASO DO CONJUNTO HABITACIONAL SILVIA COVAS.
}

\author{
Janaína Lopes Moreira ${ }^{1}$
}

Gabriela Calderon ${ }^{2}$

\begin{abstract}
RESUMO
Este trabalho é resultado de diálogos e debates sobre os processos socioespaciais presentes no espaço urbano. Priorizou-se o processo de segregação socioespacial, o qual, devido sua multidimensionalidade e, consequentemente, complexidade, precisa ser devidamente abordado. Nesse sentido, com base em autores que estudam a temática (SPOSITO, 2013; CORRÊA; 2013), foram realizadas abordagens e elucidações que trazem contribuições para a reflexão. Para o tratamento da dimensão do real e do concreto optou-se pela escala local, com enfoque no intraurbano do município de Penápolis/SP. A área escolhida para o estudo foi o loteamento habitacional Silvia Covas, construído nos anos 2000 através da parceria entre o poder público municipal, a CDHU e os moradores. Como procedimentos metodológicos foram realizadas observações in loco, conversas informais com moradores e pesquisa no jornal local. Dessa forma, a partir da análise da dimensão econômica, social e ambiental, percebeu-se que o loteamento Silvia Covas apresenta-se segregado, principalmente como consequência da atuação do poder público, que aloja segmentos populacionais de baixa renda em lugares afastados, deteriorando suas condições de vida através da poluição ambiental, carência de serviços urbanos, insuficiência de lazer e aumento da criminalidade. Logo, fica nítido que o tratamento do poder público municipal não é somente irregular, mas distinto, o que vai transformar a diferença em negatividade, colaborando para o processo de segregação socioespacial no espaço intraurbano de Penápolis.
\end{abstract}

PALAVRAS-CHAVE: Segregação. Estado. Penápolis/SP.

\footnotetext{
${ }_{1}^{1}$ Mestranda do Programa de Pós Graduação em Geografia, Faculdade de Ciência e Tecnologia da Universidade Estadual Paulista "Julio de Mesquita Filho" - campus de Presidente Prudente. janainamoreira1991@hotmail.com.

${ }^{2}$ Mestranda do Programa de Pós Graduação em Geografia, Faculdade de Ciência e Tecnologia da Universidade Estadual Paulista "Julio de Mesquita Filho" - campus de Presidente Prudente.

gabi_calderon_@hotmail.com.
} 


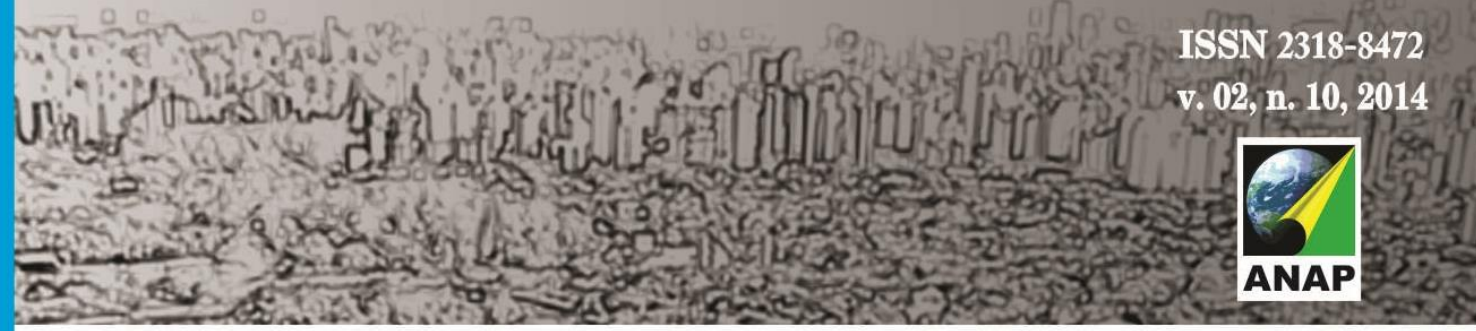

\section{Revista Nacional de}

Gerenciamento de Cidades

de lutas por melhores condições de vida, bem como demonstrou a imagem do bairro oferecida aos leitores.

\section{DESENVOLVIMENTO}

\subsection{Segregação Socioespacial}

Conforme salienta Sposito (2013) não são todas as formas de diferenciação que caracteriza a segregação, somente as diferenças mais radicais, que geram separação espacial podem ser denominadas de segregação.

O que vários autores têm privilegiado em seus trabalhos é o socioespacial ou sócio-espacial, uma vez que é a adjetivação que melhor explica a complexidade e as múltiplas dimensões do processo atualmente. Isso porque, os processos sociais, principalmente, de segmentação social como, diferenciação espacial, produção de desigualdades espaciais, exclusão social e/ou espacial, discriminação social entre outros, ocorrem preteritamente ao processo de segregação, porém este só se viabiliza por meio do espaço (SPOSITO, 2013). Portanto, só o conceito de segregação socioespacial consegue refletir todas as relações que se dão no espaço, e por ele são determinadas.

Ainda de acordo com a autora supracitada, para a abordagem da segregação é necessário levar em consideração duas determinações: a subjetiva e a objetiva. A primeira diz respeito aos sentimentos e discursos atribuídos aos diversos espaços das cidades, o que permite entender como as pessoas se sentem e percebem esses diferentes espaços. Como salienta Roma

\footnotetext{
Podem existir por exemplo, pessoas que se sentem afastadas, isoladas ou marginalizadas por residirem em determinados espaços, mesmo que não se autodenominem como segregadas. Para apreender a dimensão subjetiva do processo de segregação socioespacial é preciso, também, analisar como os moradores de outros espaços da cidade percebem os referidos espaços segregados (2008, p. 34).
}

Deste modo, a partir da subjetividade do conceito, a segregação pode ser considerada tanto uma ação de quem segrega em relação a quem está segregado, 


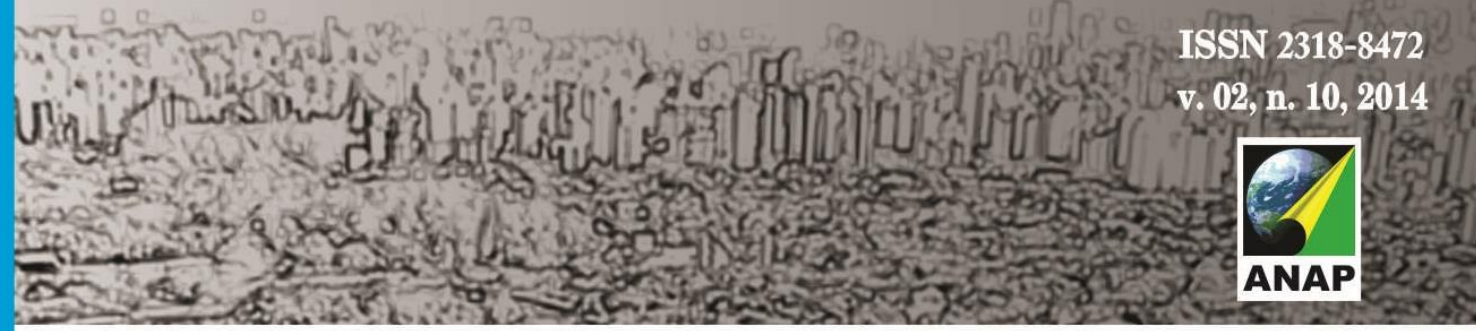

\section{Revista Nacional de}

Gerenciamento de Cidades

quanto um sentimento de quem está segregado. Sentimento este que é incorporado e reproduzido pelos moradores dessas áreas, os quais muitas vezes têm vergonha de dizer o local onde residem. Através disso, a segregação é reafirmada, criando uma série de estigmas que irão aprofundar ainda mais a separação entre os diferentes segmentos sociais existentes na cidade.

A dimensão objetiva é mais visível devido a sua materialidade. Esta se refere à separação de grupos sociais no espaço urbano, segundo seu poder aquisitivo, ou seja, nitidamente vê-se o afastamento entre ricos e pobres, e a formação de áreas residenciais que demonstram a atividade exercida pelos moradores, como por exemplo os bairros operários e industriais.

Mesmo possuindo uma perspectiva diferente sobre o conceito de segregação, Corrêa aponta tal situação quando fala que:

A segregação residencial da cidade capitalista emerge a partir da localização diferenciada no espaço urbano dessas distintas classes sociais e suas frações. Admite-se, assim, que quanto mais intensa a fragmentação social, mais complexa será a segregação residencial (2013, p.42).

É nesse sentido que Corrêa (2013) aponta a cidade contemporânea como um mutável mosaico social, haja vista que as diversas classes sociais presentes na cidade se diferenciam, tanto no tocante a distribuição residencial quanto a sua composição social, formando áreas sociais com tendência a homogeneidade interna e a heterogeneidade entre elas.

A segregação socioespacial vai se manifestar espacialmente, de modo que a separação entre os segmentos sociais se faça através de barreiras, físicas ou não, como muros, cercas e até mesmo a distância. Esse fato no espaço urbano brasileiro pode ser percebido através da implantação de loteamentos e condomínios fechados, o aparecimento de favelas e as lógicas que orientam a localização dos conjuntos habitacionais (ROMA, 2008).

Nesse sentido, um novo elemento deve ser incorporado na abordagem do conceito, visto que a segregação procede e participa das estratégias dos atores e produtores do espaço urbano. Sendo assim, é importante compreender quem são os 


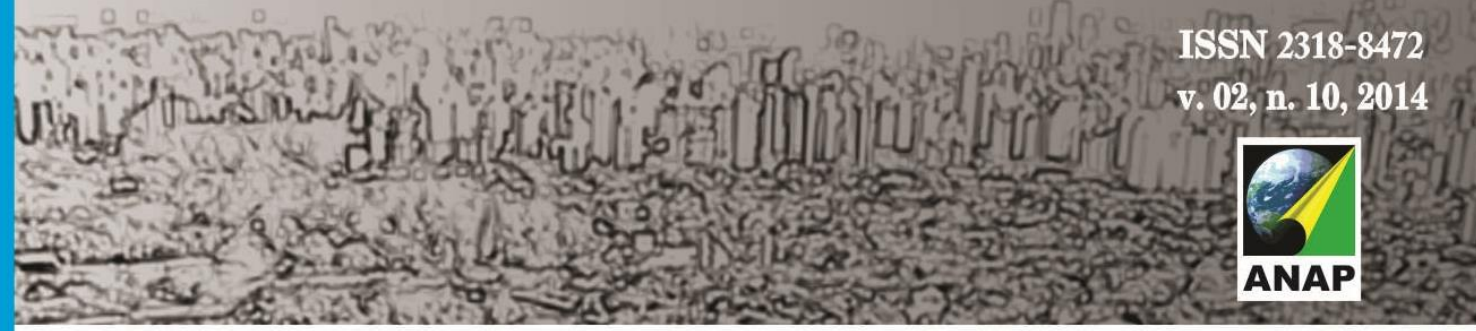

\title{
Revista Nacional de
}

Gerenciamento de Cidades

capitalistas que ocorrem na cidade, que se realiza através dos agentes imobiliários (construtoras, promotores imobiliários, rentistas, empresas de crédito imobiliário, corretores e proprietários de terras) que precisam da valorização do solo para a obtenção do lucro.

Esses vazios que se intercalam entre o tecido urbano consolidado e os conjuntos habitacionais, serão valorizados a partir do estabelecimento do saneamento básico, da iluminação, do asfalto e aruamento, da construção de equipamentos e serviços, como posto de saúde, creche, escolas, posto policial, áreas de lazer entre outros, cuja responsabilidade de construção é do Estado.

Sobre isso Namur ressalta que

\begin{abstract}
Assim sendo, ao prover de infraestrutura de transportes e de serviços as áreas isoladas da trama urbana, o Poder Público agrega valor a cada propriedade, principalmente ás áreas vazias e seu entorno imediato, independente da vontade de cada proprietário; este valor representa um ganho privado, ou melhor, trata-se de uma apropriação privada de valor produzido coletivamente, na forma de renda fundiária (2004, p. 59).
\end{abstract}

Essa valorização vinda de investimento de terceiros, especialmente do Estado, é o que chamam de "especulação imobiliária". Entretanto, esses investimentos do poder público poderiam ser menores, no que se refere aos custos, se as áreas já urbanizadas ou contíguas a malha urbana fossem escolhidas (NAMUR, 2004).

Sendo assim, o Estado atua de forma heterogênea no espaço urbano, provocando o aprofundamento do processo de diferenciação socioespacial, visto que também produz áreas para a burguesia, provendo acessibilidade, infraestruturas urbanas e equipamentos sociais, os quais geram a valorização imobiliária. Portanto, a ação do Estado como produtor do espaço urbano, por meio da escolha da localização de conjuntos habitacionais de interesse social, tem gerado grandes ganhos imobiliários aos proprietários de terra em detrimento a qualidade de vida da população (NAMUR, 2004). E é nesse cenário que o bairro Silvia Covas foi construído no município de Penápolis/SP. 


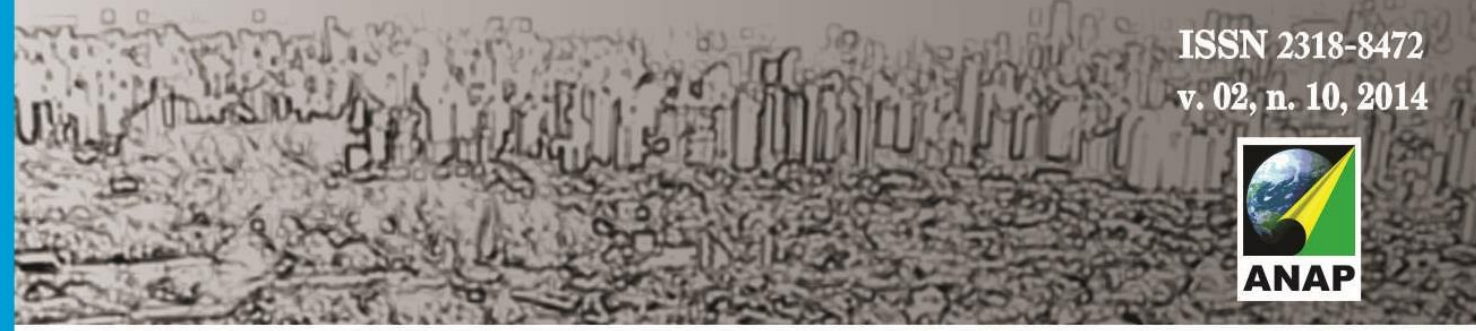

\section{Revista Nacional de}

Gerenciamento de Cidades

\subsection{O Bairro Silvia Covas - Contextualização}

O bairro em estudo localiza-se na cidade de Penápolis (Figura 01) no noroeste paulista e sua implantação se deu nos anos 2000 através de políticas habitacionais que iniciaram nos anos de 1980 no Brasil. A política habitacional que permeou a implantação desse bairro foi a mesma de vários outros conjuntos habitacionais em outras cidades, que consiste na doação de uma área comprada pela prefeitura para a CDHU (Companhia de Desenvolvimento Habitacional e Urbano do Estado de São Paulo), a qual segundo alguns critérios estabelecidos em um manual, pode aceitar ou recusar.

As moradias foram construídas a partir de alianças com os movimentos populares organizados em associações através do programa de mutirão, o que significa que a execução da obra realizou-se por autoconstrução, isto é, com o Programa Cesta de Materiais de Construção, criado em 1995, pelo então governador Mário Covas, os próprios moradores construíam suas casas. Esses programas eram destinados à população com renda de um à dez salários mínimos, e prioritariamente voltados para as famílias com renda até três salários mínimos (NAMUR, 2004).

O projeto do conjunto habitacional foi coordenado pela Emurpe (Empresa Municipal de Urbanização de Penápolis), que resultou na construção de 500 casas que custaram ao morador 30 mil reais cada, as quais foram financiadas em 300 parcelas. 


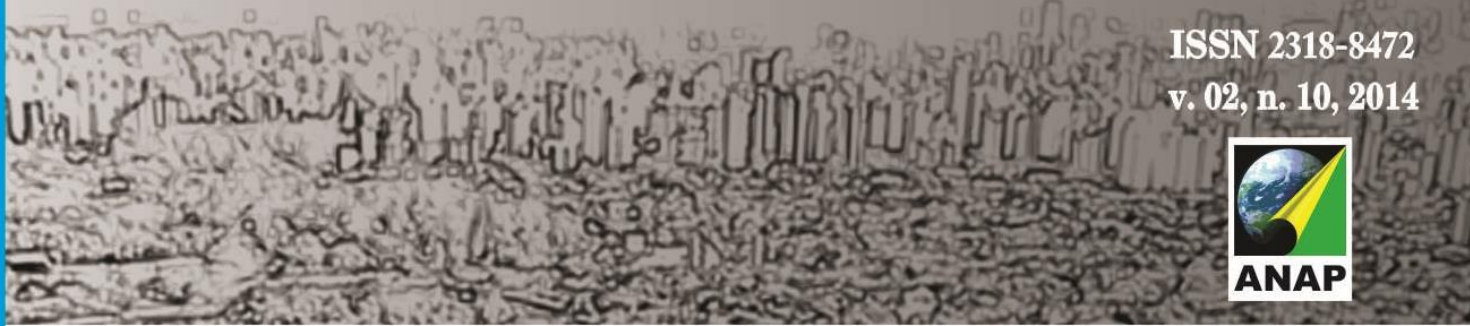

\section{Revista Nacional de}

Gerenciamento de Cidades

Figura 02: Localização do bairro Silvia Covas na malha urbana do município de Penápolis/SP.

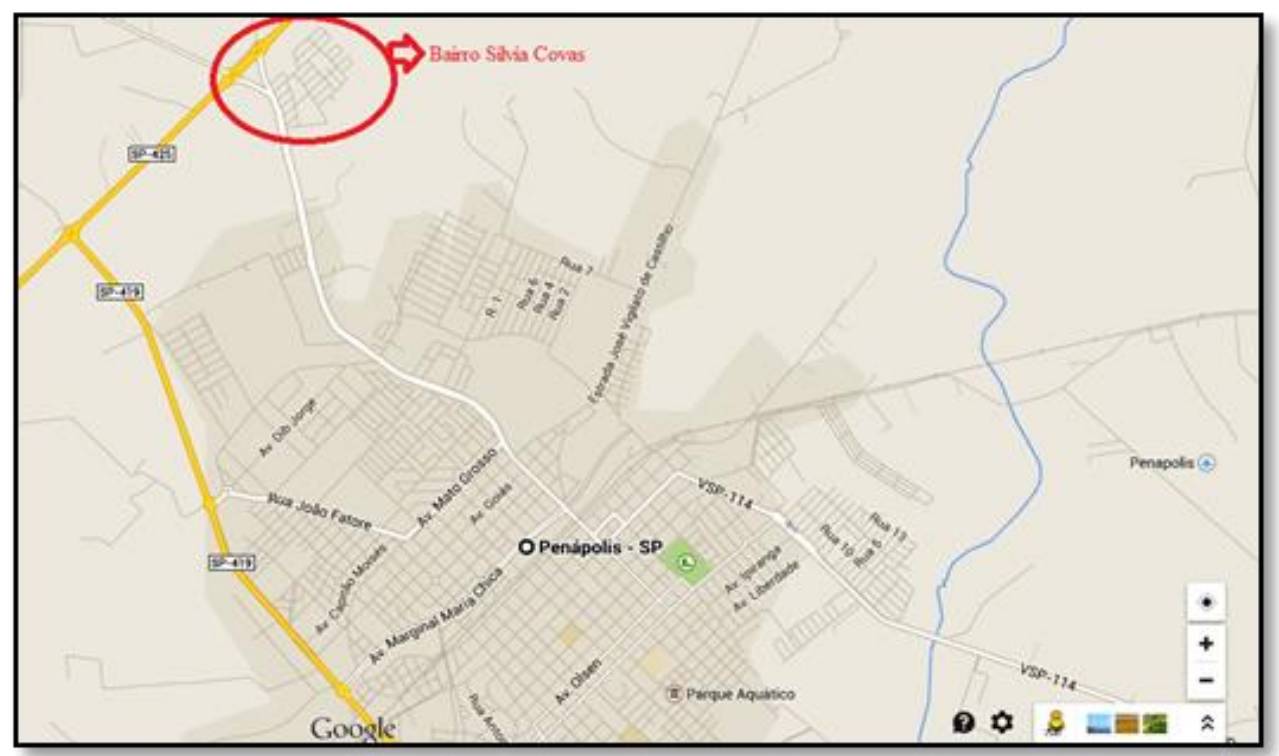

Fonte: Google Mapas. Agosto de 2014.

No que tange a dimensão econômica podemos citar: os altos custos dos serviços urbanos, como transporte e comércio, que exige da população residente maiores salários para que suas condições básicas de vida sejam supridas; os diferentes valores de troca de imóveis urbanos que surgem segundo a distribuição de infraestruturas e equipamentos urbanos, causando consequentemente, a valorização de áreas bem atendidas em detrimento a outras áreas menos equipadas; e por fim a especulação imobiliária, visto que a partir da instalação do loteamento e a construção de infraestrutura e serviços pelo poder público, todas as áreas vazias de entorno são imediatamente valorizadas (Figura 03). 


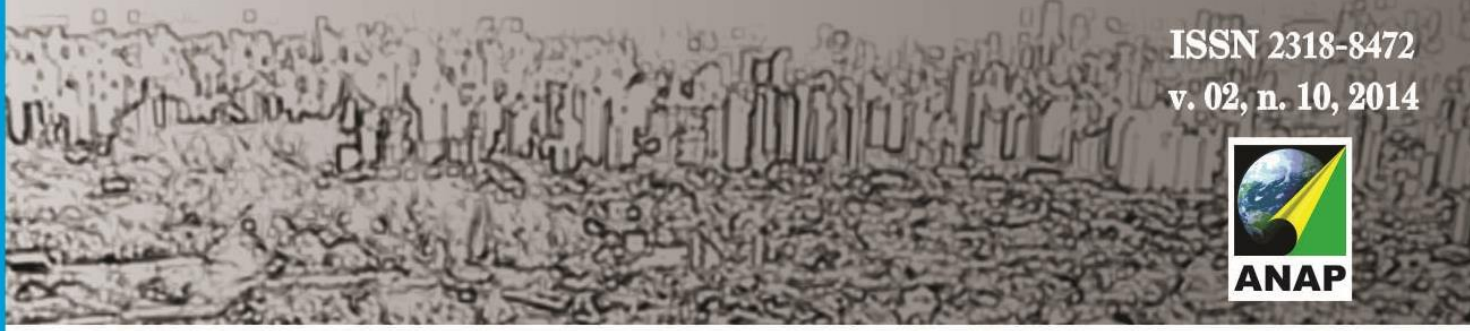

\section{Revista Nacional de}

Gerenciamento de Cidades

Figura 03: Vazios urbanos entre o bairro Silvia Covas e o centro da cidade.

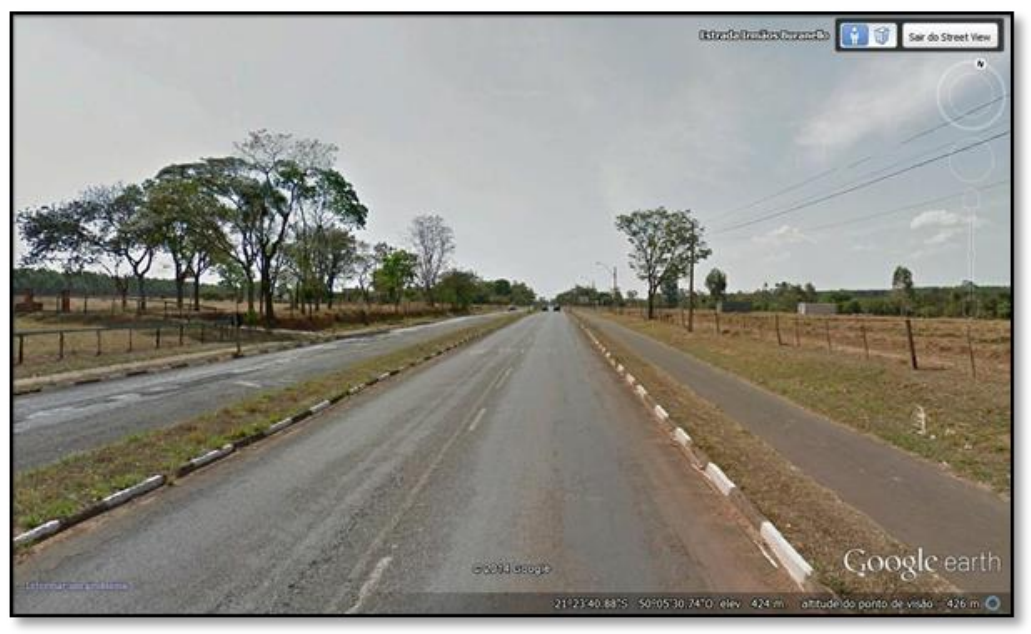

Fonte: Google Earth. Agosto de 2011.

Essas características vão incidir diretamente na questão social, uma vez que a distribuição irregular de infraestruturas e a distância das melhores áreas equipadas torna nítida a forma irregular de atuação do Estado, bem como a separação das classes sociais, com pessoas de melhor poder aquisitivo residindo em áreas onde há boa infraestrutura e amenidades e pessoas de menor poder aquisitivo residindo em periferias com infraestrutura precária ou inexistente. Tais fatos desfavorecem a inserção socioespacial dos moradores a cidade, fazendo com que diferenças sociais inerentes à urbanização se aprofundem colaborando para o processo de segregação residencial.

A respeito da questão ambiental, destaca-se a falta de manutenção e planejamento do poder público municipal, visto que o bairro apresenta-se com sérios problemas de degradação ambiental decorrentes do descarte incorreto de materiais recicláveis e lixo em terrenos vazios nos arredores do bairro (Figuras 04 e 05). Além disso, têm-se ocorrências de queimadas de lixo e mato que os próprios moradores fazem, na tentativa de melhorar a aparência do loteamento, já que o mesmo apresenta-se com vários vazios em seu interior, vastas áreas de gramado e mata. 


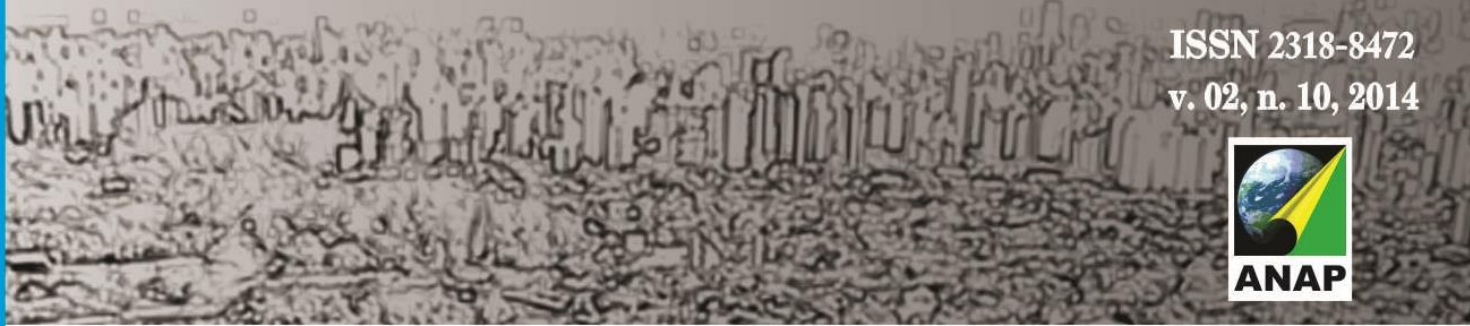

Revista Nacional de

Gerenciamento de Cidades

Figuras 04 e 05: Lixo e entulho espalhados pelos terrenos vazios nos arredores do bairro
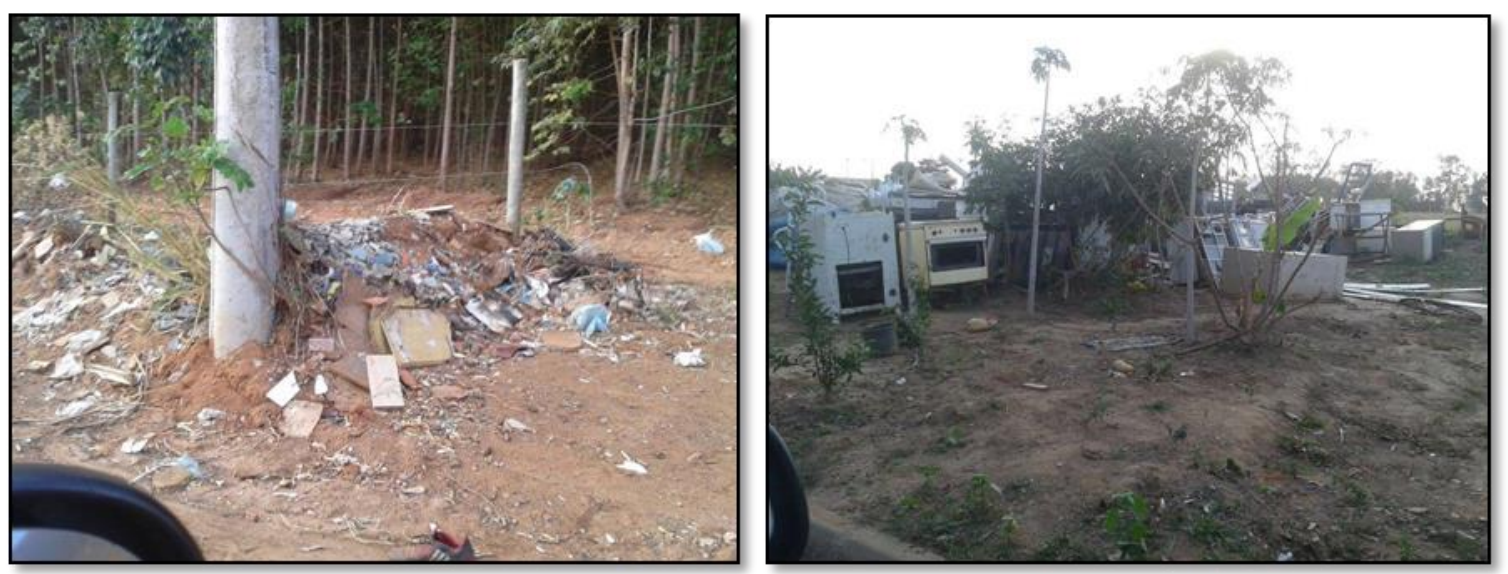

Fonte: Trabalho de campo. Agosto de 2014.

\subsubsection{Caracterização da área de estudo}

Ainda em visita a campo, observou-se os meios de consumo coletivo, podendo verificar que alguns serviços públicos e privados do local ainda são insuficientes para a demanda do bairro ou até mesmo inexistentes.

O bairro atualmente possui todas as ruas pavimentadas. Com início em 2008, depois de quase 8 anos da entrega dos domicílios, a pavimentação asfáltica foi concluída, conquista essa marcada por lutas e reivindicações dos moradores.

O bairro também possui: uma creche EMMEI Silvia Covas que atende crianças de 0 a 3 anos; uma EMEF (Escola Municipal de Ensino Fundamental Professora Darcy Aparecida Buranello Marin), inaugurada no dia 17/01/2004, e reinaugurada como CEU (Centro Educacional Unificado) no dia 17/04/2005, passando a funcionar em tempo integral, formando alunos do $1^{\circ}$ ao $5^{\circ}$ ano do ensino fundamental (Figuras 06 e 07). 


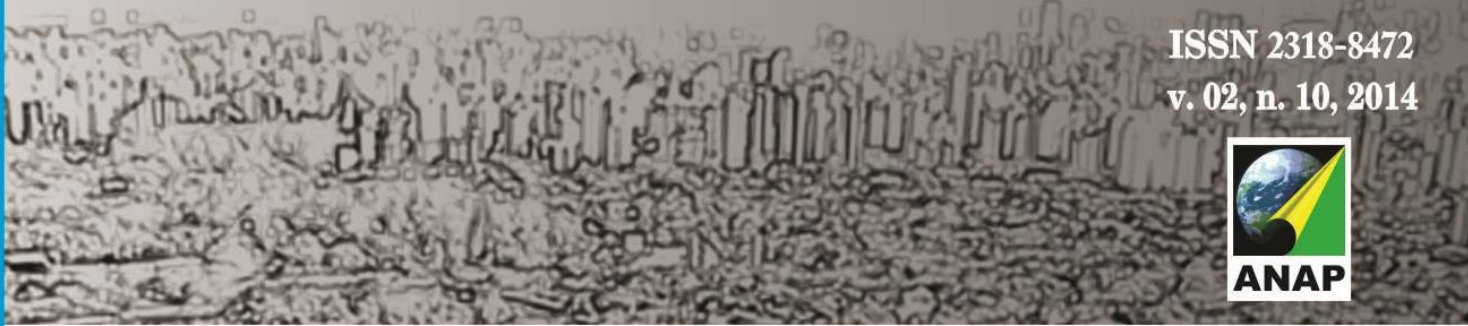

Revista Nacional de

Gerenciamento de Cidades

Figuras 06 e 07: Creche EMMEI Silvia Covas e Escola Municipal de Ensino Fundamental Professora Darcy Aparecida Buranello Marin (EMEF).
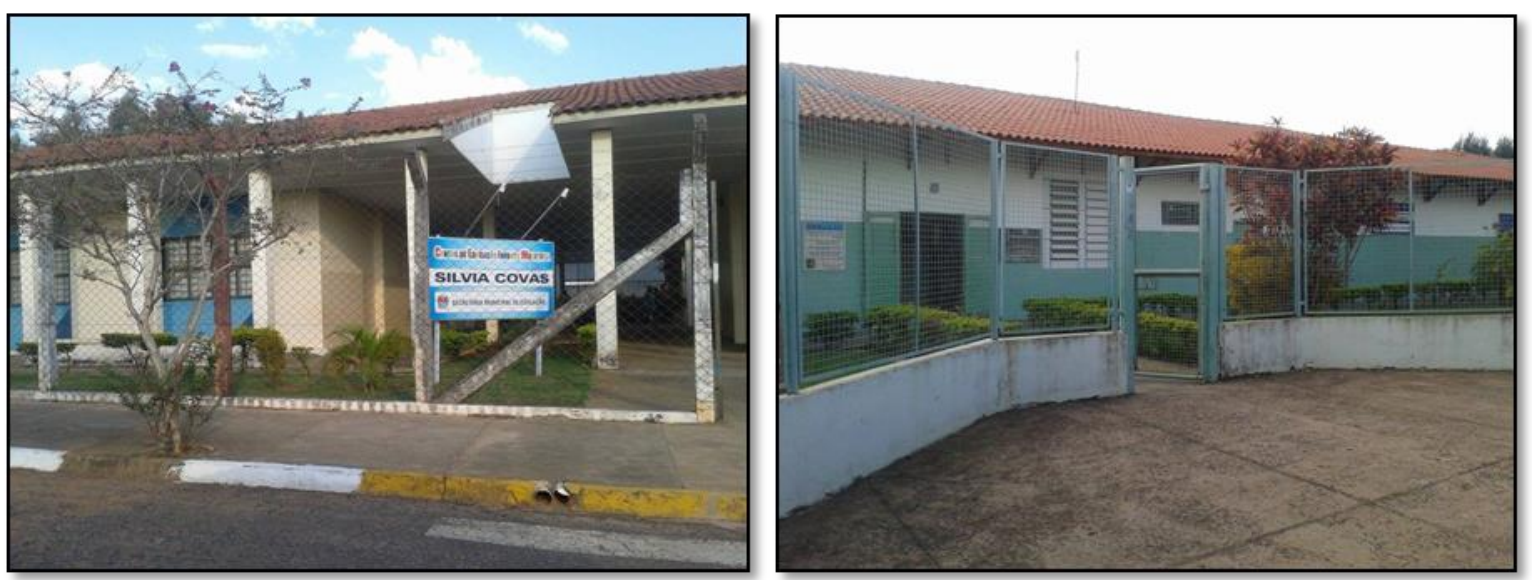

Fonte: Trabalho de campo. Agosto de 2014.

Os alunos moradores do bairro que estão cursando séries superiores precisam frequentar outras unidades escolares localizadas em bairro próximos. No entanto, como informado pela secretaria de educação, a Prefeitura de Penápolis oferece transporte a todos.

O loteamento também dispõe de uma Unidade Básica de Saúde, a qual iniciou seu funcionamento em 2007 e oferece atendimento até às 17h. Atualmente, o prédio está em obras para ampliação (Figuras 08 e 09).

Figuras 08 e 09: Unidade Básica de Saúde Silvia Covas e obras em andamento para a ampliação
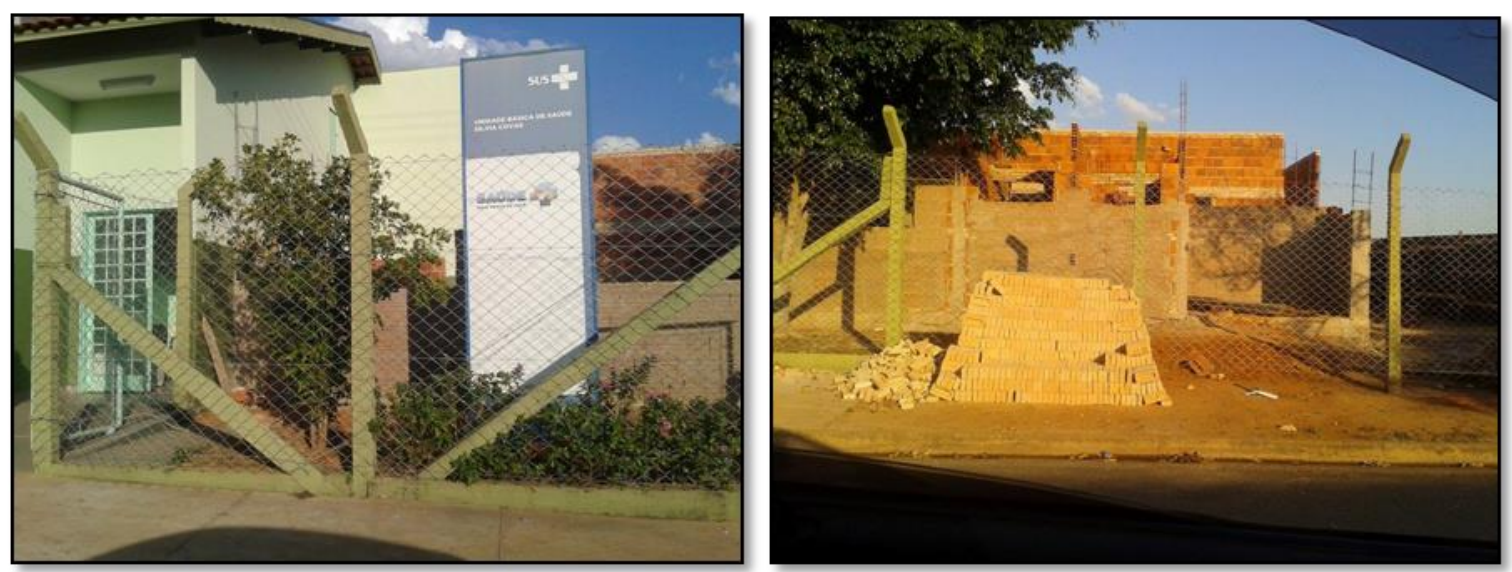

Fonte: Trabalho de campo. Agosto de 2014. 


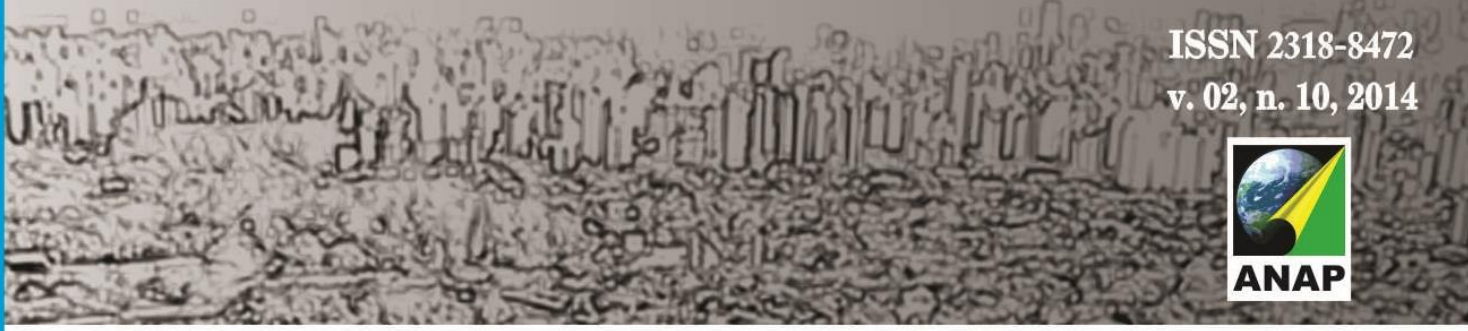

Revista Nacional de

Gerenciamento de Cidades

Observou-se também que o bairro não possui posto policial e alguns comércios, como por exemplo, farmácia e supermercado. Há apenas uma mercearia, bares e padarias que não oferecem todos os suprimentos básicos aos moradores. Além disso, em caso de emergência e/ou de necessidade de atendimento médico após as $17 \mathrm{~h}$, os moradores precisam recorrer a Santa Casa de Misericórdia que se localiza no centro da cidade.

Foi notado também que existe apenas uma via de acesso ao bairro, que se dá através da Estrada Irmãos Buranello, na qual há um significativo fluxo de veículos, já que a mesma é utilizada para a entrada e saída do município e que por isso se apresenta como uma via perigosa, mesmo possuindo ciclovia. A partir disso e da grande distância do centro da cidade, os moradores fazem muito uso do transporte público, o qual se mostra mais seguro e barato.

A grande deficiência atual do bairro diz respeito à espaços de lazer e recreação, o qual mesmo dispondo de grandes áreas de gramado não possui praças ou parques no interior ou no entorno próximo. Tem-se apenas uma quadra esportiva que aparentemente precisa de reparos (Figuras 10 e 11).

Figuras 10 e 11: Quadra esportiva e vazios urbanos no interior do loteamento.
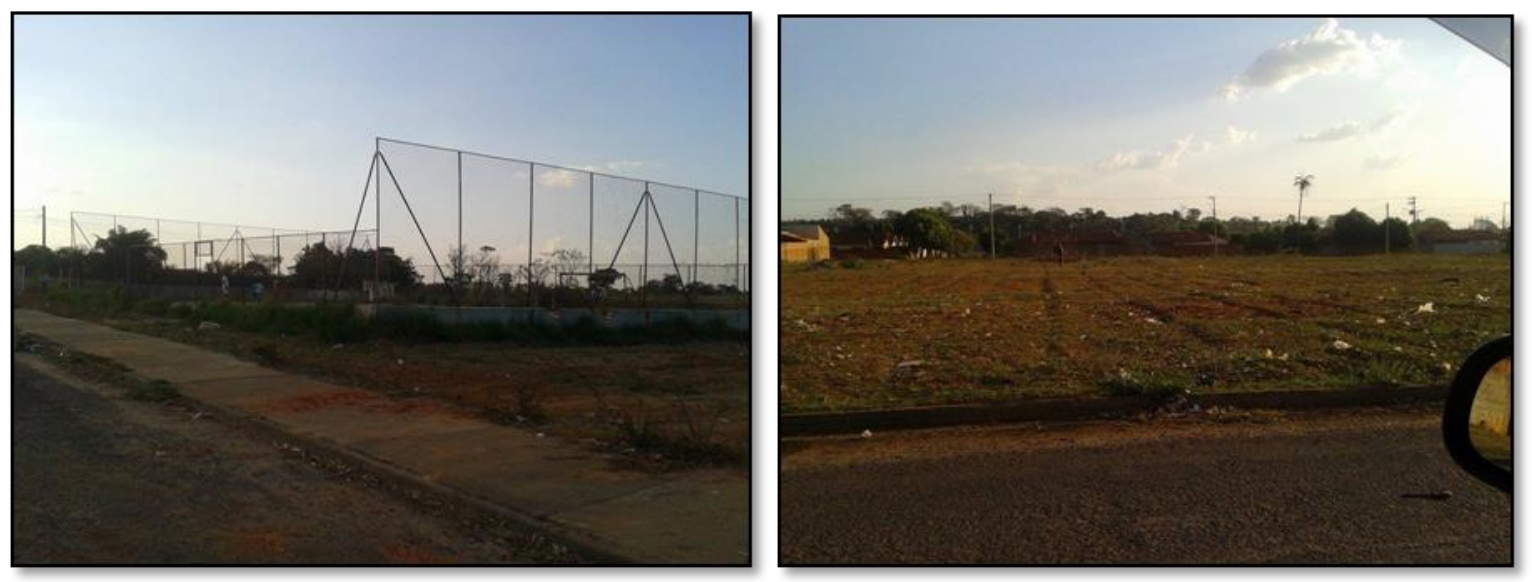

Fonte: Trabalho de campo. Agosto de 2014. 


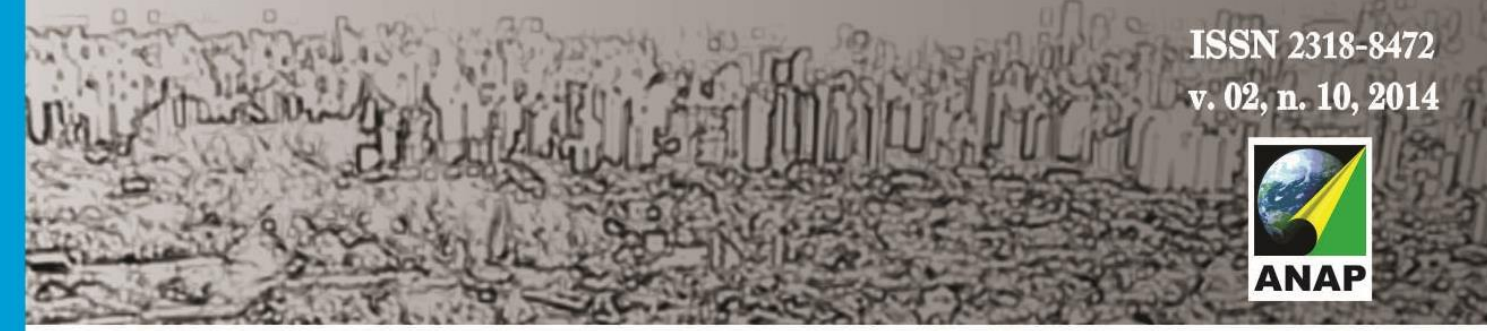

\section{Revista Nacional de}

Gerenciamento de Cidades

\subsubsection{O noticiário local}

Além das observações empíricas, foi realizada uma pesquisa online na página do jornal Diário de Penápolis ${ }^{3}$ com 0 intuito de verificar em que tipos de notícias o Bairro Silvia Covas é citado.

Durante os primeiros anos após a entrega dos domicílios, todas as notícias que envolviam o bairro diziam respeito a denúncias e reivindicações dos moradores, sobretudo, no que se refere à pavimentação asfáltica.

- "Novela do asfalto irrita comunidade do Silvia Covas" em 31/03/2007.

- "Silvia Covas: Cansada de promessas, comunidade quer asfalto já." em 14/07/2007.

- "Assinado contrato para pavimentação do Sílvia Covas" em 07/05/2008.

- "Começa obra de pavimentação no Sílvia Covas" em 15/06/2008.

Entretanto, não foi somente a pavimentação das vias que se tornaram notícias, outras reivindicações e reclamações dos moradores também tiveram destaque no jornal.

- "Silvia Covas: Moradores reclamam cobertura para ponto de ônibus." em 04/07/2007.

- "Matagal no Sílvia Covas é alvo de reclamação." em 23/01/2008.

- "Orçamento Participativo: Moradores do Sílvia Covas reivindicam melhorias." em 14/02/2008.

- "Silvia Covas: moradores destacam pontos positivos e negativos do bairro" em 14/04/2010.

- "OCORRÊNCIA: Fogo em pastagem assusta moradores do Silvia Covas." em 10/05/2012.

- "Quadras esportivas dos bairros Sílvia Covas e Pevi permanecem com estragos." em 16/08/2012.

\footnotetext{
${ }^{3}$ Site do Jornal Diário de Penápolis - Disponível em:

<http://www.diariodepenapolis.com.br/web/busca>, Acesso em 25/08/2014.
} 


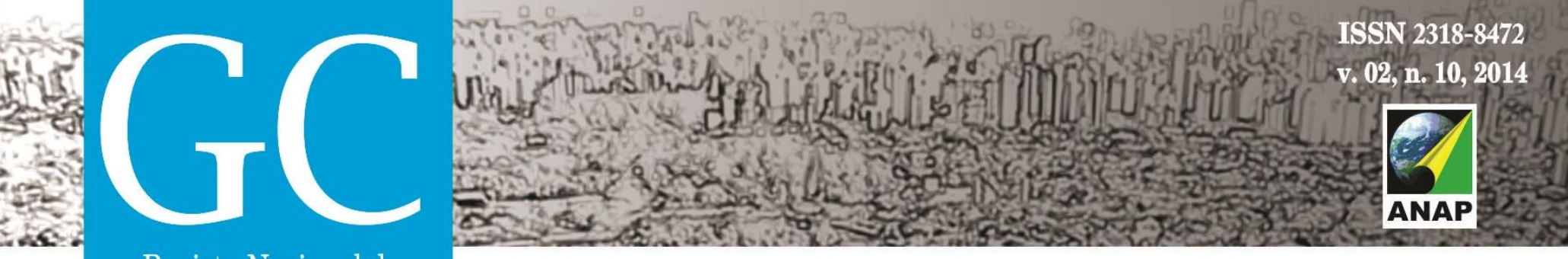

\section{Revista Nacional de}

Gerenciamento de Cidades

CORRÊA, R. L. Segregação residencial: as classes sociais e o espaço urbano. In: VASCONCELOS, P. A.; CORREAA, R. L.; PINTAUDI, S. M. A cidade contemporânea. Segregação Espacial. 1.ed. São Paulo: Contexto, 2013, v.1, p. 39-59.

NAMUR, M. . A questão da localização no processo de produção pública habitacional da CDHU no espaço urbano. Ambiente Construído (Online), v.4, n.1, p. 55-66, 2004.

ROMA, C. M. Segregação socioespacial em cidades pequenas. 2008. 137f. Dissertação (Mestrado em Geografia) - Faculdade de Ciência e Tecnologia, Universidade Estadual Paulista, Presidente Prudente.

SPOSITO, M. E. B. Segregação socioespacial e centralidade urbana. In: Pedro de Almeida Vasconcelos; Roberto Lobato Corrêa; Silvana Maria Pintaudi. A cidade contemporânea. Segregação Espacial. 1. ed. São Paulo: Contexto, 2013, v.1, p. 61-93 